
$\angle$ Research Square
Preprints are preliminary reports that have not undergone peer review.
They should not be considered conclusive, used to inform clinical practice,
or referenced by the media as validated information.

\title{
Parenchyma sparing strategy and oncological prognosis in patients with colorectal cancer liver metastases
}

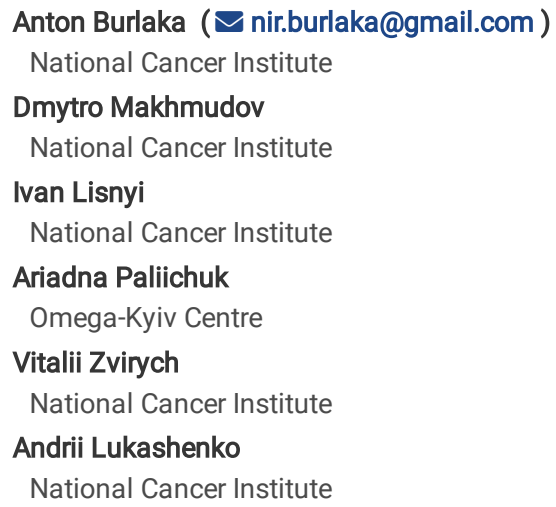

\section{Research Article}

Keywords: parenchyma sparing surgery, colorectal cancer, bilobar metastases

Posted Date: February 8th, 2022

DOI: https://doi.org/10.21203/rs.3.rs-1309143/v1

License: (c) (1) This work is licensed under a Creative Commons Attribution 4.0 International License. Read Full License

Version of Record: A version of this preprint was published at World Journal of Surgical Oncology on April 17th, 2022. See the published version at https://doi.org/10.1186/s12957-022-02579-1. 


\section{Abstract}

Background: preliminary study results demonstrated parenchyma sparing surgery (PSS) as an effective approach which allowed to remove colorectal cancer (CRC) metastatic lesions within the central liver cites and increased the probability of the liver re-resections.

Methods: the prospective analysis re-evaluation of the 185 CRC patients surgical treatment has been performed.

Results: an overall 5 -year survival (OS) of the 185 enrolled patients was $43 \pm 7 \%$, the mean and median value for OS was $48,7 \pm 1.9 \%$ and $55,2 \pm 5$ ( $95 \%$ Cl: 44,4 - 66,1) months. While CRC patients OS whose metastatic lesions were predominantly located within peripheral and central liver segments was $56 \pm 8 \%$ and $27 \pm 9 \%$ respectively $(p=0,08)$. A 5 -year disease-free survival rates of patients with peripheral and central liver cites metastatic lesions was $31 \pm 7 \%$ and $15 \pm$ $7 \%, p=0,12$.

Conclusions: parenchyma sparing surgery should be a priority pathway for complex treatment of patients with deeply located lesions of the right liver lobe.

Trial registration: study registered in https://www.researchregistry.com/browse-the-registry, № 5679.

\section{Background}

About 1.8 million new cases of colorectal cancer (CRC) are diagnosed worldwide yearly. CRC is ranged 3rd in the structure of the most common malignant neoplasms in Ukraine [1]. Throughout the natural history of CRC $>50 \%$ of patients develop liver metastases [2]. Proper liver resection strategy is the cornerstone of metastatic CRC treatment, because only a successful liver resection significantly improves long-term treatment outcomes (e.g. complete removal of metastatic lesions allows to achieve an overall survival rate of 43-65\%) [3]. Most liver resections for CRC demonstrate low postoperative morbidity and mortality rates [4]. However there is a subcategory of CRC patients with bilobar spread of lesions who require major resections (removal of ${ }^{3} 3$ anatomical liver segments). Extent of surgery strongly correlates with an increased risk of acute liver failure as well as complications in the early postoperative period [5]. In these cases treatment success depends on a sufficient amount of future liver remnant ranging from 30 to $40 \%$ of total liver volume. Taking into account the indisputable effectiveness of the surgical method, different operation strategies for bilobar forms of CRC have been developed. Artificial stimulation of future liver remnant hypertrophy via the ligation or embolization of the portal vein branches in attempt to proceed with a two-stage hepatectomy was the most prominent one, while other strategies had been introduced just recently [6]. The main disadvantage of two-stage hepatectomy strategy is the possibility of disease progression after the first surgical stage ("dropout") $[7,8]$. This leads to an inability to complete the entire liver resection, resulting in poor oncological prognosis [9]. In attempt to overcome this issue, an associating liver partition and portal vein ligation (ALPPS) strategy was introduced [10]. However ALPPS showed a significant decrease of incomplete liver resections, it was strongly associated with increased postoperative mortalit] - 15\%) [11]. An alternative strategy for bilobar CRC involves parenchyma sparing surgery (PSS) of all bilobar metastatic lesions within one surgical procedure. Such an approach is considered to be an adapted "cherry-picking technique", widely used for the subcapsular liver metastases removal [12]. Torzilli et al. expanded indications for PSS by introducing the possibility of simultaneous deep hepatic lesions removal under ultrasound guidance [13]. Such an approach seems capable of reducing the necessity of both portal vein embolization and ligation [14]. Authors have noticed that appropriate skills of intraoperative ultrasound guidance and intraparenchymal skeletization of vessels and glisonean structures of $1^{\text {st }}$ and $2^{\text {nd }}$ division from adjacent lesions by $R_{1}$ vascular detachment $\left(\mathrm{R}_{1 \mathrm{v}}\right)$ approach [15]. However, the results of the PSS in cases of deeply localized lesions ("right venous core", portal or caval confluences etc.) remain to be unclear. We have recently published the first results of the PSS study within the central and peripheral liver sites [16]. Preliminary study results demonstrated PSS as an effective approach which allowed to remove metastatic lesions within the central liver cites and increased the probability of the liver re-resections.

The aim of this article was to show the long-term oncological results of PSS strategy for CRC liver surgery.

\section{Methods}

The prospective analysis re-evaluation of the $185 \mathrm{CRC}$ patients surgical treatment has been performed. The description of the liver surgery aspects, study design, inclusion and exclusion criteria, endpoints have previously been published [17]. Statistical analysis has been performed with Prizm 8.0 for macOS, 8.4.2 version. The normality variables distribution has been checked by the Shapiro - Wilk test. $\mathrm{P}=0.05$ was taken as the critical level of significance when testing statistical hypotheses. Patients' overall (OS) and disease-free survival (DFS) has been analyzed according to the Kaplan-Meier method. The multivariate Cox regression analysis of factors contributing to overall survival of CRC patients has been performed.

\section{Results}

An overall 5-year survival (OS) of the 185 enrolled patients was $43 \pm 7 \%$, the mean and median value for OS was $48,7 \pm 1.9 \%$ and $55,2 \pm 5$ ( $95 \%$ Cl: $44,4-66,1)$ months. While CRC patients OS whose metastatic lesions were predominantly located within peripheral and central liver segments was $56 \pm 8 \%$ and $27 \pm 9 \%$ respectively $(p=0,08)$, (Fig.1A). OS median in the same groups was estimated as $60,3 \pm 4,6(95 \% \mathrm{Cl}: 51,4-69,3)$ and $46,5 \pm 6,5(95 \% \mathrm{Cl}$ : $33,7-59,3)$ months respectively (Fig.1A).

There weren't statistical differences in 5-year OS between cohorts of the patients with $R_{1 v}$ and $R_{0}$ resection margin, $48 \pm 7 \%$ and $13 \pm 12 \%$ respectively, $p=$ 0,67 (Fig. 1B). A 5-year DFS of patients with peripheral and central liver cites metastatic lesions was $31 \pm 7 \%$ and $15 \pm 7 \%, p=0,12$ (Fig. 1C). Whereas cohort $(n=27)$ of CRC patients with $R_{1 v}$ margin didn't reach a 5-year follow-up, the DFS median was 34,2 and 46,5 months for $R_{1 v}$ and $R_{0}$ cohorts respectively, $p=$ 0,62 (Fig. 1D). 
In attempt to comprehensively assess the risks of survival and their relation to independent clinical and surgical factors, we performed a comparative analysis of the existing database (see table 3 ).

Table 1

Univariate and multivariate analysis for overall survival prognosis

\begin{tabular}{|c|c|c|c|c|c|}
\hline & \multicolumn{3}{|c|}{ Univariate } & \multicolumn{2}{|c|}{ Multivariate } \\
\hline & $\mathrm{n}$ & Median, months & $\mathrm{P}$ & B-factor & $\mathrm{P}$ \\
\hline \multicolumn{6}{|c|}{ Preoperative factors: } \\
\hline T1-2 & 27 & - & \multirow[t]{2}{*}{0,32} & 0,54 & 0,21 \\
\hline T3-4 & 158 & 31,6 & & & \\
\hline N- & 93 & - & \multirow[t]{2}{*}{0,24} & $-0,34$ & 0,44 \\
\hline $\mathrm{N}+$ & 78 & 30,9 & & & \\
\hline M0 & 82 & - & \multirow[t]{2}{*}{0,21} & 0,98 & 0,79 \\
\hline M1 & 103 & 39,2 & & & \\
\hline \multicolumn{6}{|c|}{ Primary tumor site: } \\
\hline Right colon & 28 & 25,4 & \multirow[t]{2}{*}{0,52} & $-0,83$ & 0,13 \\
\hline Left colon & 157 & - & & & \\
\hline \multicolumn{6}{|c|}{ Lung metastases } \\
\hline Yes & 18 & 16,7 & \multirow[t]{2}{*}{0,001} & $-0,41$ & 0,53 \\
\hline No & 167 & - & & & \\
\hline KRAS-status & & & & 2,3 & 0,001 \\
\hline Mutation & 48 & 14,6 & 0,001 & & \\
\hline Wild type & 137 & - & & & \\
\hline \multicolumn{6}{|c|}{ Tumor burden of the liver } \\
\hline \multicolumn{6}{|c|}{ Number of metastatic sites: } \\
\hline $1-5$ & 99 & 39,2 & \multirow[t]{2}{*}{0,67} & $-0,67$ & 0,12 \\
\hline$>5$ & 86 & 25,4 & & & \\
\hline \multicolumn{6}{|c|}{ Size of metastatic lesion*: } \\
\hline$<50 \mathrm{~mm}$ & 132 & 66,2 & \multirow[t]{2}{*}{0,99} & 0,36 & 0,45 \\
\hline$\geq 50 \mathrm{~mm}$ & 53 & 35,1 & & & \\
\hline \multicolumn{6}{|c|}{ Involved segments } \\
\hline $1-3$ & 127 & - & \multirow[t]{2}{*}{0,001} & 0,96 & 0,02 \\
\hline$\geq 4$ & 58 & 14,6 & & & \\
\hline \multicolumn{6}{|c|}{ Predominant location of metastatic lesions } \\
\hline Central & 78 & - & \multirow[t]{2}{*}{0,3} & 0,35 & 0,46 \\
\hline Periphereal & 107 & 37,4 & & & \\
\hline \multicolumn{6}{|c|}{ Surgical factors } \\
\hline \multicolumn{6}{|c|}{ Resection margin: } \\
\hline $\mathrm{R}_{0}$ & 158 & - & 0,44 & $-0,66$ & 0,91 \\
\hline $\mathrm{R}_{1 \mathrm{v}}$ & 27 & 28,1 & & & \\
\hline
\end{tabular}

Acknowledgement. "-" - median survival not reached at the time of analysis, * - in case of multiple lesions, the largest lesion size was chosen; B - Beta coefficient; In current equation, the independent variable is the overall cumulative survival rate. 
Table 3 contains data from univariate and multivariate analysis (MVA) of risk assessment for overall cumulative survival depending on a number of surgical and clinical factors. According to univariate analysis, the overall survival significantly depended on the presence of lung metastases. MVA variables depended on the presence of KRAS mutation and the involvement of $\geq 4$ anatomical liver segments.

\section{Discussion}

The modern concept of CRC is based on the perception of the metastatic process as a chronic illness and not as a lethal disease [18]. That is why we believe that PSS has significant advantages for patients with bilobar metastases of CRC from both pathophysiological and oncological points of view in comparison with two-stage hepatectomies. Our results suggest that adapted PSS strategy was effective for multiple bilobar liver metastases removal regardless of their organ distribution and the number of simultaneously removed lesions. Hence, MVA did not demonstrate any significant impact of excised lesions number on the overall survival. On the contrary, it has been proved that PSS provides perspectives for further successful adjuvant treatment. According to the different sources, about $60 \%$ of operated patients have recurrent metastatic liver lesions, while PSS increases the likelihood of re-resection in such patients. Thus, out of 185 operated patients, 1, 2, 3, 4 and 5 liver resections have been performed in 115 (62.2\%), $36(19.4 \%), 25(13.5 \%), 14$ (7, $5 \%)$ and 1 (0.5\%) cases respectively. We consider this result as satisfactory, given that $1 / 3$ of patients had bilobar metastatic lesions and more than $1 / 2$ of the patients had recurrent metastatic lesions of the operated parenchyma and successfully underwent re-resection. We believe that a multidisciplinary team should consider several options for systemic anticancer therapy and surgical treatment, including PSS strategy that may be appropriate for most patients with recurrent metastatic disease. Furthermore, the use of non-toxic chemotherapy regimens that will not increase the level of postoperative complications is a fundamentally important factor in the success of the above-mentioned treatment. It has been proven that administering more than 12 cycles of chemotherapy can lead to unacceptable levels of postoperative complications and mortality [19]. The survival results from our study refer to worldwide accepted results - the overall 5-year survival rate was $43 \pm 7 \%$. We want to emphasize, that authors who apply the principles of PSS in treatment of CRC are positive regarding the safety of $1 \mathrm{~mm}$ resection margin and $\mathrm{R}_{1 \mathrm{v}}$ resections, which have been mentioned as key components of the entire PSS strategy [20]. Moreover, this study revealed that the resection margin status $\left(R_{0} / R_{1 v}\right)$ had no impact on OS rate in either univariate analysis or MVA.

Finally, a successful implementation of PSS reduces the necessity of performing technically complex vascular approaches (ALPPS, portal vein ligation or embolization and "major" resections), which represent a threat to the oncological effect of treatment, especially in cases of an unsuccessful 1 st stage hepatectomy.

\section{Conclusions}

Parenchyma sparing surgery has shown appropriate surgical and oncological outcomes of treatment of the colorectal cancer patients with bilobar liver metastases. Parenchyma sparing surgery should be a priority pathway for complex treatment of patients with deeply located lesions of the right liver lobe.

\section{Abbreviations}

1. Associating liver partition and portal vein ligation - ALPPS

2. Colorectal cancer - CRC

3. Disease-free survival - DFS

4. Parenchyma sparing surgery - PSS

5. Multivariate analysis - MVA

6. Overall survival - OS

7. $R_{1}$ vascular detachment $-R_{1 v}$

\section{Declarations}

\section{Acknowledgements.}

The authors thank the patients who participated in this study.

\section{Ethics approval and consent to participate:}

This study was approved by the institutional ethics review committee at the National Cancer Institute, Kyiv, Ukraine (IRB number: 88, 18-Jan-2017). This work was in conformity with the principles of the Helsinki Declaration. All the participants signed informed consent and voluntarily joined the study before treatment.

\section{Funding.}

The authors disclosed receipt of the following financial support for the research, authorship, and/or publication of this article: This work was supported by the Ministry of Health of Ukraine, (https://moz.gov.ua). 


\section{Declaration of Conflicting Interests:}

the authors declare that they have no conflicts of interests.

\section{Consent for publication:}

patients signed informed consent regarding publishing their data.

\section{Availability of data and materials:}

not applicable

\section{Contributions:}

this study was conceived and written by A. Burlaka.

D. Makhmudov performed the paper translation. Data collection and analysis were performed by I. Lisnyi, A. Paliichuk, V. Zvirych. A. Lukashenko has directed the project. All authors read and approved the manuscript.

\section{References}

1. Katona BW, Weiss JM. Chemoprevention of Colorectal Cancer. Gastroenterology. 2020;158(2):368-388. doi:10.1053/j.gastro.2019.06.047

2. Kaminski MF, Robertson DJ, Senore C, Rex DK. Optimizing the Quality of Colorectal Cancer Screening Worldwide. Gastroenterology. 2020;158(2):404-417. doi:10.1053/j.gastro.2019.11.026

3. Kaminski MF, Robertson DJ, Senore C, Rex DK. Optimizing the Quality of Colorectal Cancer Screening Worldwide. Gastroenterology. 2020;158(2):404-417. doi:10.1053/j.gastro.2019.11.026

4. Aghayan DL, Kazaryan AM, Dagenborg VJ, Røsok BI, Fagerland MW, Waaler Bjørnelv GM, Kristiansen R, Flatmark K, Fretland ÅA, Edwin B; OSLO-COMET Survival Study Collaborators. Long-Term Oncologic Outcomes After Laparoscopic Versus Open Resection for Colorectal Liver Metastases : A Randomized Trial. Ann Intern Med. 2021 Feb;174(2):175-182. doi: 10.7326/M20-4011. Epub 2020 Nov 17. PMID: 33197213.

5. Lafaro K, Buettner S, Maqsood H et al (2015) Defining post hepatectomy liver insufficiency: where do we stand? J Gastroin- test Surg Off J Soc Surg Alimentary Tract 19:2079-2092

6. Martin J, Petrillo A, Smyth EC, Shaida N, Khwaja S, Cheow HK, Duckworth A, Heister P, Praseedom R, Jah A, Balakrishnan A, Harper S, Liau S, Kosmoliaptsis V, Huguet E. Colorectal liver metastases: Current management and future perspectives. World J Clin Oncol. 2020 Oct 24;11(10):761-808. doi: 10.5306/wjco.v11.i10.761. PMID: 33200074; PMCID: PMC7643190.

7. Kawaguchi Y, Lillemoe HA, Vauthey JN. Dealing with an insufficient future liver remnant: Portal vein embolization and two-stage hepatectomy. J Surg Oncol. 2019 Apr;119(5):594-603. doi: 10.1002/jso.25430. Epub 2019 Mar 1. PMID: 30825223; PMCID: PMC6422720.

8. Viganò L, Torzilli G, Cimino M, Imai K, Vibert E, Donadon M, Castaing D, Adam R. Drop-out between the two liver resections of two-stage hepatectomy. Patient selection or loss of chance? Eur J Surg Oncol. 2016;42:1385-1393.

9. Faitot F, Faron M, Adam R, Elias D, Cimino M, Cherqui D. Two-stage hepatectomy versus 1-stage resection combined with radiofrequency for bilobar colorectal metastases: a case-matched analysis of surgical and oncological outcomes. Ann Surg. 2014 Nov;260(5):822-7; discussion 827-8. doi: 10.1097/SLA.0000000000000976.

10. Moris D, Ronnekleiv-Kelly S, Kostakis ID, Tsilimigras DI, Beal EW, Papalampros A. Operative Results and Oncologic Outcomes of Associating Liver Partition and Portal Vein Ligation for Staged Hepatectomy (ALPPS) Versus Two-Stage Hepatectomy (TSH) in Patients with Unresectable Colorectal Liver Metastases: A Systematic Review and Meta-Analysis. World J Surg. 2018 Mar;42(3):806-815. doi: 10.1007/s00268-017-4181-6.

11. Moris D, Ronnekleiv-Kelly S, Kostakis ID, Tsilimigras DI, Beal EW, Papalampros A, Dimitroulis D, Felekouras E, Pawlik TM. Operative Results and Oncologic Outcomes of Associating Liver Partition and Portal Vein Ligation for Staged Hepatectomy (ALPPS) Versus Two-Stage Hepatectomy (TSH) in Patients with

12. Unresectable Colorectal Liver Metastases: A Systematic Review and Meta-Analysis. World J Surg. 2018 Mar;42(3):806-815. doi: 10.1007/s00268-0174181-6. PMID: 28798996.

13. Krausch M, Raffel A, Anlauf M, Schott M, Lehwald N, Krieg A, Topp SA, Cupisti K, Knoefel WT. "Cherry picking", a multiple non-anatomic liver resection technique, as a promising option for diffuse liver metastases in patients with neuroendocrine tumours. World J Surg. 2014 Feb;38(2):392-401. doi: 10.1007/s00268-013-2267-3. PMID: 24101025.

14. Torzilli G, Procopio F, Botea F, Marconi M, Del Fabbro D, Donadon M, Palmisano A, Spinelli A, Montorsi M: One-stage ultrasonographically guided hepatectomy for multiple bilobar colorectal metastases: a feasible and effective alternative to the 2-stage approach. Surgery 2009;146:60-71.

15. Torzilli G, Cimino M: Extending the Limits of Resection for Colorectal Liver Metastases enhanced one stage surgery. J Gastroint Surg, 2016; $10.1007 / \mathrm{s} 11605-016-3250-8$. 
16. Torzilli G, Procopio F, Costa G: Adjuncts to hepatic resection - ultrasound and emerging guidance systems; in: Jarnagin WR, Belghiti J, Blumgart LH: Blumgart's Surgery of the Liver, Pancreas, and Biliary Tract. Edn 5, Philadelphia, Elsevier Saunders. 2012, vol. 2, pp 1604-1649.

17. Burlaka AA, Paliichuk AV, latsyna OI, Kolesnik OO. Colorectal cancer liver metastases within the central and peripheral segments: Parenchymal sparing surgery adaptation. Ann Med Surg (Lond). 2020;58:8-13. Published 2020 Aug 14. doi:10.1016/j.amsu.2020.07.052

18. Di Nicolantonio F, Vitiello PP, Marsoni S, Siena S, Tabernero J, Trusolino L, Bernards R, Bardelli A. Precision oncology in metastatic colorectal cancer - from biology to medicine. Nat Rev Clin Oncol. 2021 Apr 16. doi: 10.1038/s41571-021-00495-z. Epub ahead of print. PMID: 33864051.

19. Dörr NM, Bartels M, Morgul MH. Current Treatment of Colorectal Liver Metastasis as a Chronic Disease. Anticancer Res. 2020 Jan;40(1):1-7. doi: 10.21873/anticanres.13921. PMID: 31892548.

20. Moris D, Ronnekleiv-Kelly S, Rahnemai-Azar AA, Felekouras E, Dillhoff M, Schmidt C, Pawlik TM. Parenchymal-Sparing Versus Anatomic Liver Resection for Colorectal Liver Metastases: a Systematic Review. J Gastrointest Surg. 2017 Jun;21(6):1076-1085. doi: 10.1007/s11605-017-3397-y. Epub 2017 Mar 31. PMID: 28364212.

\section{Figures}
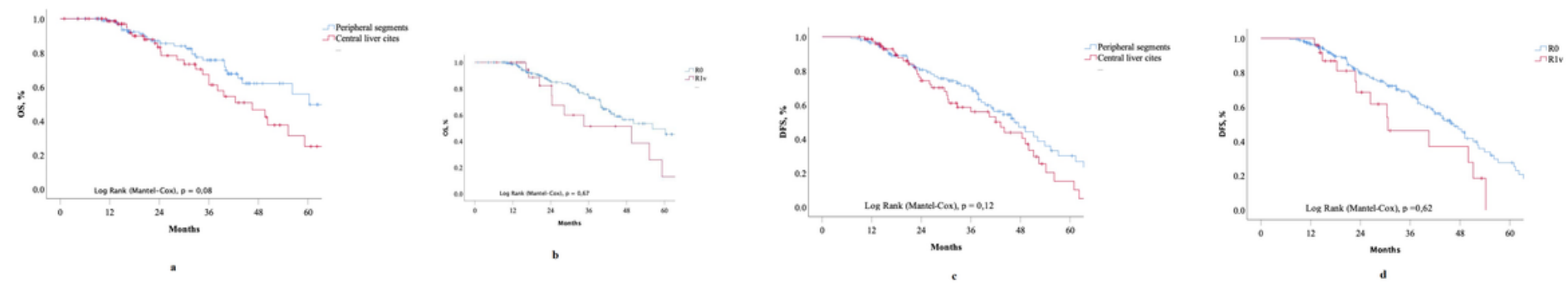

\section{Figure 1}

Kaplan-Meier plots:

A - OS of CRC patients with predominant localizations of the metastatic lesions within the peripheral $(n=107)$ and central $(n=78)$ liver segments.

$B$ - OS of CRC patients with liver parenchyma resection margin stratification $\left(R_{0}\right.$ and $R_{1}$ vascular detachment in 158 and 27 patients respectively).

C - Disease-free survival of CRC patients with predominant localizations of the metastatic lesions withing the peripheral $(n=107)$ and central $(n=78)$ liver segments.

D - Disease-free survival of CRC patients with liver parenchyma resection margin stratification $\left(R_{0}\right.$ and $R_{1}$ vascular detachment in 158 and 27 patients respectively). 